DOI: $10.1590 / 1089-6891 v 20 \mathrm{e}-47184$

CIÊNCIA E TECNOLOGIA DE ALIMENTOS

\title{
QUEIJO ARTESANAL PRODUZIDO NO SUL DO RIO GRANDE DO SUL: AVALIAÇÃO FÍSICO-QUÍMICA, MICROBIOLÓGICA E SUSCETIBILIDADE A ANTIMICROBIANOS DE ISOLADOS DE STAPHYLOCOCCUS COAGULASE POSITIVA
}

\author{
ARTISANAL CHEESE PRODUCED IN THE SOUTH OF RIO GRANDE DO \\ SUL: PHYSICAL-CHEMICAL, MICROBIOLOGICAL ASSESSMENT AND \\ SUSCEPTIBILITY OF ANTIMICROBIALS FROM STAPHYLOCOCCUS \\ COAGULASE POSITIVE ISOLATES
}

\author{
Alana Borges Tavares ${ }^{1^{*}}$ ORCID - http://orcid.org/0000-0001-9590-3541 \\ Eduarda Aléxia Nunes Louzada Dias Cavalcanti ${ }^{1}$ ORCID - http://orcid.org/0000-0002-4898- \\ $\underline{7428}$ \\ Cláudio Dias Timm¹ ORCID - http://orcid.org/0000-0003-3920-9066 \\ Helenice Gonzalez de Lima1 ORCID - http://orcid.org/0000-0003-4567-5119 \\ Natacha Deboni Cereser ${ }^{1}$ ORCID - http://orcid.org/0000-0002-3263-0512 \\ 'Universidade Federal de Pelotas, Pelotas, RS, Brasil. \\ *Autora para correspondência - alana_btavares@yahoo.com.br
}

\section{Resumo}

Objetivando o conhecimento do queijo colonial artesanal produzido na região Sul do Rio Grande do Sul, foram analisadas 30 amostras adquiridas no comércio local e feiras quanto às características físico-químicas, além das análises microbiológicas exigidas pela Agência Nacional de Vigilância Sanitária (ANVISA), isolamento de Yersinia enterocolitica e resistência aos antimicrobianos de isolados de Staphylococcus coagulase positiva, obtidos a partir destas amostras. Os valores medianos resultantes das análises físico-químicas foram: $\mathrm{pH} 5,81$, acidez titulável de $0,44 \mathrm{~g}$ de ácido lático/100g, umidade de 48,55\%, atividade de água de 0,973 , proteína de 19,36\%, gordura de $14,54 \%$, teor de cinzas de $2,88 \%$ e teor de cloretos $0,51 \mathrm{gNaCl} / 100 \mathrm{~g}$. Quanto às análises exigidas pela ANVISA, $86,66 \%$ das amostras estavam fora dos padrões exigidos e nenhuma foi positiva para Salmonella e Listeria monocytogenes. Houve também isolamento de Yersinia enterocolitica em 3,33\% das amostras. A maior taxa de resistência dos isolados de Staphylococcus coagulase positiva ocorreu frente à Penicilina $\mathrm{G}$ com $100 \%$ dos isolados resistentes e a menor contra Ciprofloxacina com nenhum isolado resistente. $65,00 \%$ dos isolados foram resistentes a, pelo menos, seis antimicrobianos e $86,95 \%$ demostraram resistência à Cefoxitina, resultados preocupantes, especialmente quanto aos isolados Meticilina Resistentes. Além disso, o queijo produzido e comercializado informalmente no Sul do Rio Grande do Sul apresenta grande variação nas características físico-químicas e, em geral, alta contaminação microbiana, podendo representar risco à saúde do consumidor.

Palavras-chave: saúde pública; Yersinia enterocolitica; lácteos; suscetibilidade.

\footnotetext{
Abstract

Aiming the knowledge of the artisanal colonial cheese produced in the south of the Rio Grande do Sul, were analyzed 30 samples purchased in the local trade and fairs for physicochemical characteristics, the microbiological analyzes required by the National Agency of Sanitary Surveillance (ANVISA), Yersinia enterocolitica isolation and antimicrobial resistance of Staphylococcus coagulase positive
} 
isolates obtained from these samples. The median values resulting from the physicochemical analyzes were, $\mathrm{pH} 5,86$, titratable acidity of $0,49 \mathrm{~g}$ of lactic acid/100 g, humidity of 49,12\%, water activity of 0,973 , protein of $19,14 \%$, fat of $14,71 \%$ Ash content of $2,93 \%$ and chloride content $0,63 \mathrm{gNaCl} / 100 \mathrm{~g}$. Regarding the analysis required by ANVISA $86,66 \%$ of the samples were outside the required standards and no samples were positive for Salmonella and Listeria monocytogenes, there was also isolation to isolate Yersinia enterocolitica from 3,33\% of the samples. The highest resistance rate of the isolates of Staphylococcus coagulase positive was compared to Penicillin G with $100 \%$ of the resistant isolates, and the lowest against Ciprofloxacin with no resistant isolates. $65.00 \%$ of the isolates were resistant to at least six antimicrobials and 86,95\% demonstrated resistance to Cefoxitin, a troubling result, especially in Methicillin Resistant isolates. The cheese produced and marketed informally in South of Rio Grande do Sul presents a great variation in the physicochemical characteristics and in general high microbial contamination wich may represent a risk to consumer health.

Keywords: public health; Yersinia enterocolitica; dairy; susceptibility.

Recebido em: 29 de maio de 2017

Aceito em: 16 de maio de 2019

\section{Introdução}

O queijo colonial produzido no sul do Rio Grande do Sul não possui regulamentação técnica, é produzido, em geral, a partir da adição de coalho ao leite cru, formando a massa na qual é adicionado o sal e pressionada em formas para retirada do soro. É comercializado geralmente sem maturação(1), representando um risco maior de transmissão de patógenos devido ao seu alto teor de umidade.

Segundo o último Censo Agropecuário ${ }^{(2)}, 25.348$ toneladas de queijo ou requeijão são produzidas e comercializadas diretamente ao consumidor por pequenos produtores e 70.198 toneladas são vendidos a intermediários. Diante dessa realidade, as autoridades sanitárias têm trabalhado para buscar a regularização desse tipo de produção visando a eliminação da comercialização de produtos informais. Assim, foi publicada a Instrução Normativa (IN) n ${ }^{\circ} 30$ de 07 de agosto de 2013, que pretende expandir as regiões produtoras de queijos artesanais com registro de Indicação Geográfica $(\mathrm{IG})^{(3)}$, e mais recentemente da IN n ${ }^{\circ} 5$ de 14 de fevereiro de 2017, que flexibiliza normas de instalações de pequenas indústrias ${ }^{(4)}$.

Alimentos artesanais costumam atrair consumidores que valorizam os traços regionais ${ }^{(5)}$. Muitos produtores rurais, visando esse mercado e na tentativa de gerar uma renda extra, acabam produzindo esses alimentos em sua propriedade de maneira informal, sem inspeção sanitária, podendo assim, carrear patógenos responsáveis por causar doenças transmitidas por alimentos (DTAs).

Além dos micro-organismos monitorados em alimentos pelos órgãos oficiais, há outros que causam danos à saúde do consumidor, como a Yersinia enterocolitica frequentemente isolada de produtos de origem animal e associada à infecção com sintomatologia gastrointestinal, podendo evoluir para linfadenite mesentérica e infecções sistêmicas, causando em alguns casos, até a morte do paciente ${ }^{(6)}$.

Outro problema enfrentado pelas autoridades mundiais de saúde é a resistência a antimicrobianos, cada vez mais frequentemente encontrada em isolados bacterianos ${ }^{(7)}$. No Brasil, em 2009, foi implantado o Plano Nacional de Controle de Resíduos e Contaminantes (PNRC) pelo Ministério da Agricultura, Pecuária e Abastecimento, cujo intuito é limitar o avanço da resistência de micro-organismos e evitar 
a exposição dos consumidores a compostos químicos como antibióticos ${ }^{(8)}$, mas esse controle acaba ficando limitado devido à comercialização de produtos não inspecionados.

Apesar do risco, queijos artesanais produzidos sem inspeção sanitária são amplamente consumidos na região Sul do Rio Grande do Sul. Assim, o objetivo deste trabalho foi conhecer as características físico-químicas e a qualidade microbiológica, além de demonstrar o possível risco sanitário do queijo produzido de forma artesanal.

\section{Material e métodos}

Foram analisadas 30 amostras de queijos coloniais, fabricados artesanalmente e comercializados nas cidades de Canguçu, Rio Grande, Pelotas, São Lourenço do Sul, Pedro Osório e Morro Redondo, localizadas na região Sul do Rio Grande do Sul. As amostras foram adquiridas diretamente nos pontos de venda, mantidas em embalagem original, transportadas em caixa isotérmica contendo gelo, e analisadas pelo Laboratório de Inspeção de Produtos de Origem Animal (LIPOA) da Universidade Federal de Pelotas.

As análises foram realizadas com base em metodologia descrita pelo Ministério da Agricultura Pecuária e Abastecimento (MAPA), vigente no período do experimento ${ }^{(9)}$. Para isso, as amostras foram analisadas quanto:

a) Valor de $\mathrm{pH}$ a partir do método potenciométrico;

b) Acidez titulável com base em ácido lático buscando a neutralização do ácido a partir de titulação com hidróxido de sódio e posterior cálculo de acordo com o volume de álcali gasto;

c) Cloretos através do método Argentométrico, utilizando titulação com nitrato de prata e indicador cromato de potássio, a partir do resíduo obtido na análise de cinzas e posterior cálculo com base no volume de solução de titulação gasta;

d) Gordura a partir do método butirométrico adaptado ao butirômetro de leite que visa a separação e quantificação dos lipídios com o auxilio de ácido sulfúrico e álcool isoamílico;

e) Proteína a partir da digestão da amostra, adicionada de mistura catalítica e ácido sulfúrico, em tubo Kjeldahl, destilação com utilização de soluções de ácido bórico e hidróxido de sódio e titulação com ácido clorídrico fazendo-se posterior cálculo relacionando a quantidade de nitrogênio encontrada na análise e \% de proteína correspondente;

f) Umidade a partir da retirada de água da amostra com o auxílio de estufa a $102 \pm 2^{\circ} \mathrm{C}$ e calculando-se a diferença entre as pesagens antes e após a evaporação.

Foi determinado também teor de cinzas com base em metodologia estabelecida pelo Instituto Adolfo Lutz, na qual a amostra foi transformada em cinzas com o auxílio de mufla a $550{ }^{\circ} \mathrm{C}^{(10)}$. A atividade de água (aW) foi avaliada no equipamento Labtouch aw (Novasina).

As análises microbiológicas realizadas foram as exigidas pela ANVISA para queijos de alta umidade, que são: contagem de Staphylococcus coagulase positiva, contagem de coliformes termotolerantes, pesquisa de Salmonella e Listeria monocytogenes ${ }^{(11)}$, conforme metodologia do MAPA vigente $^{(12)}$. Além disso, foi realizado também o isolamento de Yersinia enterocolitica, segundo Vidon e Delmas ${ }^{(13)}$ 
e posterior análise molecular para a confirmação. Para a extração do DNA dos isolados suspeitos de Y. enterocolitica foi utilizada metodologia descrita por Sambrook \& Russel ${ }^{(14)}$. Após essa etapa os DNAs extraídos foram submetidos à reação em cadeia da polimerase conforme Neubauer et al ${ }^{(15)}$ utilizando os primers: Y1 - 5' AATACCGCATAACGTCTTC 3' e Y2 - 5' CTTCTTCTGCGAGTAACGTC 3'.

Foram submetidos ao teste de difusão em disco 23 isolados de Staphylococcus coagulase positiva obtidos na técnica de contagem, segundo metodologia descrita pelo Clinical and Laboratory Standards Institute ${ }^{(16)}$. O teste foi realizado utilizando antimicrobianos de uso comum: Ampicilina $10 \mu \mathrm{g}$, Azitromicina $15 \mu \mathrm{g}$, Cefoxitina $30 \mu \mathrm{g}$, Ceftriaxona $30 \mu \mathrm{g}$, Ciprofloxacina $5 \mu \mathrm{g}$, Gentamicina $10 \mu \mathrm{g}$, Norfloxacina $10 \mu \mathrm{g}$ e Oxacilina $1 \mu \mathrm{g}$, Penicilina G $10 \mu \mathrm{g}$ e Tetraciclina $30 \mu \mathrm{g}$ e a interpretação dos resultados foi realizada com base em tabela publicada pelo CLSI(17).

Foram realizados testes de correlação bivariada de Spearman sobre as variáveis de $\mathrm{pH}$, acidez titulável, umidade, atividade de água, contagens de Staphylococcus coagulase positiva e Número Mais Provável de Coliformes Termotolerantes, considerando o nível mínimo de confiança de 95\%. As análises foram efetuadas por meio do software estatístico SPSS 20.0.

\section{Resultados e Discussão}

As características físico-químicas encontradas nas amostras do queijo evidenciaram grande variação, apresentando valores discrepantes quando comparados, sendo demostrada a completa ausência de padronização do queijo de produção artesanal comercializado na região sul do Rio Grande do Sul. Por este motivo, para representar cada parâmetro analisado, utilizou-se a mediana e não a média (Tabela $1)$.

Tabela 1. Mediana, valores mínimo, máximo e desvio padrão das características físicoquímicas encontradas em amostras queijo colonial artesanal, comercializado no Sul do Rio Grande do Sul

\begin{tabular}{lccc}
\hline Característica & Mediana & $\begin{array}{c}\text { Valor } \\
\text { mínimo-máximo }\end{array}$ & Desvio padrão \\
\hline pH & 5,81 & $4,95-6,95$ & 0,49 \\
Acidez titulável (g de ácido lático/100g) & 0,44 & $0,11-1,37$ & 0,24 \\
Umidade (\%) & 48,55 & $35,38-81,08$ & 8,21 \\
Atividade de água & 0,97 & $0,94-0,98$ & 0,01 \\
Proteína (\%) & 19,36 & $10,97-27,37$ & 3,39 \\
Gordura (\%) & 14,54 & $2,47-39,81$ & 7,86 \\
Resíduo mineral fixo (\%) & 2,88 & $0,84-4,32$ & 0,71 \\
Cloretos (gNaCl/100g) & 0,51 & $0,07-1,77$ & 0,52 \\
\hline
\end{tabular}

Por não conhecermos a origem e nem a qualidade da matéria-prima utilizada, não é possível afirmar, com exatidão, qual fator influenciou de maneira mais significativa nos padrões físico-químicos. Porém, sabe-se que algumas características como quantidade de proteína, gordura e resíduo mineral fixo encontradas no leite dependem do modo de produção e de fatores como a disponibilidade de forrageiras fornecidas aos bovinos, raça do animal, fase da lactação, entre outros ${ }^{(18)}$. Outro fator que pode interferir em parâmetros como proteína e gordura do queijo é a utilização de matéria-prima com alto índice de células somáticas. Essa condição altera a constituição do leite e, consequentemente, o 
rendimento e características do produto final ${ }^{(19)}$.

É possível especular ainda que, pelo menos para parte das amostras, o baixo teor de gordura encontrado poderia estar associado ao fato de os produtores realizarem o desnate da matéria-prima. A ausência de padronização na tecnologia de fabricação do queijo, também pode ter contribuído de forma significativa para os resultados das análises de umidade, atividade de água e cloretos, já que essas características são diretamente influenciadas pela metodologia de produção.

Apesar de os testes estatísticos não terem demostrado correlação entre as diferentes variáveis físicoquímicas e as contagens bacterianas, a falta de maturação, alta umidade e atividade de água interferem diretamente na multiplicação microbiana, principalmente de micro-organismos patogênicos ${ }^{(20)}$, aumentando o risco para população consumidora. Além disso, a população bacteriana inicial presente na matéria-prima, a possível contaminação durante a produção, transporte e comércio podem ter influenciado de forma significativa na variação dos valores de $\mathrm{pH}$ e acidez titulável, dada a produção de metabólitos bacterianos a partir da utilização de componentes do leite ${ }^{(21)}$.

A legislação brasileira, instituída pela ANVISA, determina os parâmetros microbiológicos para queijo a partir de uma classificação quanto ao teor de umidade ${ }^{(11)}$. As amostras analisadas tiveram percentual de umidade com mediana de $48,55 \%$, podendo ser classificadas como de alta umidade. São requisitos para este tipo de queijo: valores máximos de contagem de Staphylococcus coagulase

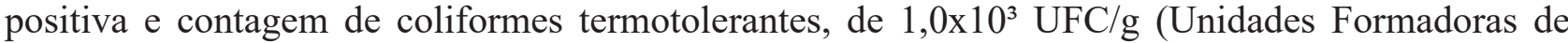

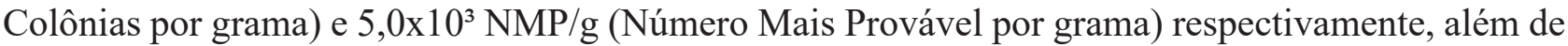
ausência de Salmonella spp. e L. monocytogenes.

Considerando esses parâmetros, pôde-se observar que apenas quatro queijos (13,33\%) estavam dentro dos padrões microbiológicos exigidos pela legislação. Das $26(86,66 \%)$ amostras consideradas fora do padrão aceitável, $24(80,00 \%)$ apresentaram contagens de Staphylococcus coagulase positiva acima do permitido. Para 13 (43,33\%) o NMP de coliformes termotolerantes estavam acima do estabelecido na legislação brasileira. Dez dos $26(38,46 \%)$ estavam com pelo menos dois parâmetros alterados. Diversos fatores podem levar à contaminação dos queijos artesanais, incluindo casos de mastite, problemas na higiene da ordenha, deficiências nas instalações, falta de higiene durante a fabricação, armazenamento do produto, transporte inadequado e exposição incorreta durante a comercialização(22).

Apesar de alarmante, o elevado número de amostras fora do padrão microbiológico, é semelhante ao encontrado por Zaffari et al. ${ }^{(23)}$ em queijos comercializados nas estradas gaúchas $(84,00 \%$ de amostras impróprias), mas menor que o encontrado por Brant et al. ${ }^{(24)}$ em queijo Minas Serro, onde $92,50 \%$ das amostras apresentavam pelo menos um parâmetro fora do estabelecido na legislação vigente.

Quanto ao número mais provável de coliformes termotolerantes obtido nas amostras, foi menor do que o observado por Brant et al. ${ }^{(24)}$ em queijo Minas Serro $(60,00 \%)$. A presença de coliformes termotolerantes indica contaminação de origem fecal, sendo E. coli, importante patógeno causador de DTA, o principal representante desse grupo ${ }^{(25)}$, a grande população observada evidencia o risco do consumo desse alimento.

Na contagem de Staphylococcus coagulase positiva, o resultado foi semelhante ao encontrado por Brant et al. ${ }^{(24)}$ em queijo Minas Serro onde $82,50 \%$ das amostras apresentavam contagens maiores do que o permitido na legislação. Brant et al. ${ }^{(24)}$ observaram diminuição na contagem de Staphylococcus coagulase positiva após estocagem durante 30 dias, sugerindo que queijos frescos podem conter números mais elevados dessa bactéria do que queijos maturados. Para esse patógeno, o manipulador constitui-se em importante fonte de contaminação durante ordenha, fabricação ou sempre que manusear o produto, já que o homem é portador de Staphylococcus aureus na pele e vias aéreas ${ }^{(26)}$. 
Dentre as amostras que se encontravam fora dos padrões exigidos pela legislação, 53,40\% e 50,00\% das que apresentavam altas contagens de coliformes termotolerantes e Staphylococcus coagulase positiva respectivamente, tinham teores de umidade igual ou superior a 50,00\%. O alto índice de umidade encontrado nas amostras, aliado ao fato de os produtos estarem expostos para a venda à temperatura ambiente sem embalagem ou proteção, pode ter contribuído também para o absurdo índice de inconformidade encontrado no nosso trabalho.

Vale ressaltar que 18 amostras (60,00\%) apresentaram contagens de Staphylococcus coagulase positiva acima de $10^{5} \mathrm{UFC} / \mathrm{g}$. Fato preocupante, já que populações acima deste valor tem maior capacidade de produzir toxinas estafilocócicas ${ }^{(26)}$ e somente no Rio Grande do Sul entre os anos de 2000 e 2002 foram relatados 57 surtos de DTAs causadas por Staphylococcus aureus deixando 1.222 pessoas doentes $^{(27)}$, destacando-se como um dos principais agentes de doenças de origem alimentar.

Todas as amostras foram negativas para a presença de Salmonella spp. e Listeria monocytogenes.

Quanto ao teste de suscetibilidade frente a antimicrobianos dos isolados de Staphylococcus coagulase positiva, a maior taxa de resistência foi com relação à Penicilina $\mathrm{G}$ com $100 \%$ dos isolados resistentes. O princípio ativo que apresentou maior eficácia contra os isolados foi a Ciprofloxacina com nenhum isolado resistente (Figura 1).

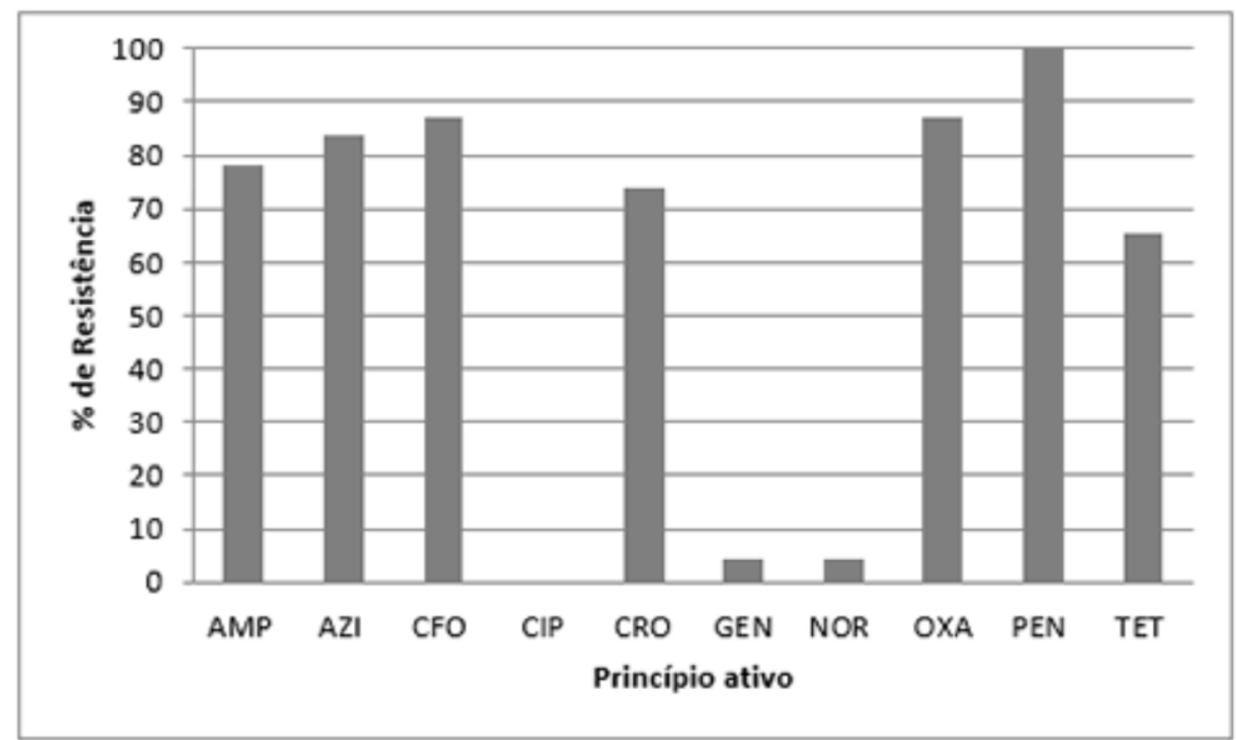

Amp: Ampicilina; Azi: Azitromicina; Cfo: Cefoxitina; Cip: Ciprofloxacina; Gen: Gentamicina; Nor: Norfloxacina; Oxa: Oxacilina; Pen: Penicilina G; Tet: Tetraciclina

Figura 1. Resistência a antimicrobianos de isolados de Staphylococcus coagulase positiva obtidos a partir de amostras de queijo colonial artesanal comercializados no Sul do Rio Grande do Sul.

Foi possível observar que $65,00 \%$ dos isolados apresentaram resistência a seis ou mais antimicrobianos aumentando a preocupação quanto à dificuldade no tratamento em caso de infecções em humanos. Além disso, a alta resistência a Cefoxitina (86,95\% dos isolados), usada atualmente como indicador de MRSA (Staphylococcus aureus Meticilina Resistente), torna esses resultados ainda mais preocupantes. Altos índices de resistência em isolados de Staphylococcus 
spp. têm sido relatados tanto em alimentos quanto em casos clínicos.

Infecções nosocomiais por MRSA são, atualmente, bastante documentadas devido à exposição, sem efetiva eliminação, da espécie bacteriana aos antibióticos do grupo dos beta-lactâmicos dentro do ambiente hospitalar ${ }^{(28)}$, mas também tem sido relatada a presença de cepas Meticilina resistentes em produtos de origem animal como o leite ${ }^{(29)}$, sugerindo que a administração inadequada desses antibióticos aos animais possa estar gerando resistência também.

Rapini et al. ${ }^{(30)}$ relataram resistência à penicilina em $100,00 \%$ dos isolados de Staphylococcus spp. oriundos de queijo coalho comercializado em praias brasileiras, mesmo resultado encontrado no nosso trabalho. Já quanto à Tetraciclina e Gentamicina o índice de resistência relatado pelos autores foi maior quando comparado ao presente trabalho, 91,00\% e 71,00\% respectivamente. A resistência à Oxacilina foi maior no nosso trabalho com relação a esse que foi de $66,70 \%$. A resistência de Staphylococcus spp. frente a antimicrobianos, embora variável, é um problema enfrentado por vários países. $\mathrm{O}$ uso indiscriminado de fármacos para o combate de micro-organismos no meio rural pode ser indicado como uma causa provável do isolamento dessas bactérias em alimentos e em casos de DTAs ${ }^{(7)}$. Staphylococcus aureus é o principal agente infeccioso isolado de mastite e tem sido relatada frequentemente a ocorrência de cepas resistentes aos antimicrobianos em amostras de leite oriundo de vacas com mastite ${ }^{(31)}$, podendo ser transferidas ao leite e derivados e gerar infecção de difícil tratamento em quem o consome.

Quanto ao isolamento de $Y$. enterocolitica foi possível confirmar a presença da bactéria em uma amostra totalizando $3,33 \%$, prevalência próxima à encontrada em estudo realizado no Irã, país onde a população também tem o hábito de consumir queijos produzidos artesanalmente, no qual essa bactéria foi isolada em $4,00 \%$ das amostras de queijo ${ }^{(32)}$. Trata-se de uma espécie bacteriana capaz de produzir uma infecção grave e que sobrevive em temperatura de refrigeração ${ }^{(33)}$.

Segundo o Ministério da Saúde ${ }^{(34)}$, entre os anos de 2009 a 2018 foram relatados ao Serviço de Vigilância em Saúde 2.350 surtos de doenças transmitidas por alimentos. 37,20\% sendo contraídos dentro das residências e 7,80\% envolvendo leite e derivados. Dentre os microorganismos identificados como causadores, figuram em $1^{\circ}$ lugar E. coli, presente em $23,40 \%$ dos casos e em $3^{\circ}$ lugar Staphylococcus aureus, em 9,40\%.

Apesar de diferentes trabalhos demonstrarem a falta de padronização dos produtos artesanais e o risco relacionado à sua contaminação microbiológica, boa parte da população não procura saber se o produto que está adquirindo passou por inspeção oficial ${ }^{(35)}$. Ou seja, aprecia o fato de ser um alimento de produção artesanal, mas ignora a gravidade de consumir um produto que não passou por nenhum controle sanitário, condição desafiadora para os serviços de vigilância oficiais.

\section{Conclusões}

Os queijos coloniais produzidos artesanalmente e comercializados na região Sul do Rio Grande do Sul possuem características físico-químicas muito variáveis e em sua maioria, alta contaminação microbiana, podendo causar danos à saúde de quem os consome. Além disso, foi evidenciada a presença de cepas de Staphylococcus coagulase positiva multirresistentes, com destaque para 86,95\% de amostras Meticilina resistentes. 


\section{Referências}

1. OPAS. Organização Pan-Americana da Saúde. Guias para o gerenciamento dos riscos sanitários em alimentos. Queijo Colonial. Cap.12, p.227-237, 2009.

2. IBGE. Instituto Brasileiro de Geografia e Estatística. Censo Agropecuário 2006. Brasil Grandes Regiões e Unidades da Federação. Rio de Janeiro, 2006. p.1-777.

3. Brasil. Ministério da Agricultura Pecuária e Abastecimento. Instrução normativa n॰30 de 7 de agosto de 2013. Diário Oficial da União. 2013 ago 08; seção 1.Portuguese.

4. Brasil. Ministério da Agricultura, Pecuária e Abastecimento. Instrução normativa $\mathrm{n}^{\circ} 5$ de 14 de fevereiro de 2017. Diário Oficial da União. 2017 fev 15; seção 1.Portuguese.

5. Cruz FT. Produtores, consumidores e valorização de produtos tradicionais: um estudo sobre qualidade de alimentos a partir do caso do queijo serrano dos campos de cima da serra-RS. 2012.292f. Tese (Doutorado em Desenvolvimento Rural) - Faculdade de Ciências Econômicas, Universidade Federal do Rio Grande do Sul, Porto Alegre. Disponível em: http://www.lume.ufrgs.br/handle/10183/61937 Acesso em: 29/05/2017

6. Longenberger AH, Gronostaj MP, Yee GY, Johnson L M, Lando JF, Voorhees RE, Waller K,; Weltman AC, Moll M, Lyss SB, Cadwell BL, Gladney L M, Ostroff SM. Yersinia enterocolitica infections associated with improperly pasteurized milk products: southwest Pennsylvania, March-August, 2011. Epidemioly and Infection, 2014; 142:1640-1650.

7. WHO. Antimicrobial resistance: global report on surveillance.. World Health Organization, 2014.

8. Brasil. Ministério da Agricultura, Pecuária e Abastecimento. Plano nacional de controle de resíduos e contaminantes / Ministério da Agricultura, Pecuária e Abastecimento. Secretaria de Defesa Agropecuária. Brasília : Mapa/ ACS, 2009. 23 p. Portuguese.

9. Brasil. Ministério da Agricultura, Pecuária e Abastecimento - MAPA. Instrução Normativa $N^{\circ}$ 68, de 12 de dezembro de 2006. Diário Oficial da União. 2006 dez 14; Seção 1.Portuguese.

10. Instituto Adolfo Lutz. Métodos químicos e físicos para análise de alimentos. Normas Analíticas do Instituto Adolfo Lutz. v.1, 3.ed. São Paulo: IMESP. p.13-14, 1985.

11. Brasil. Agência Nacional de Vigilância Sanitária. Resolução RDC n 12 de 02 de janeiro de 2001. Portuguese.

12. Brasil. Ministério da Agricultura, Pecuária e Abastecimento - MAPA. Instrução Normativa $n^{\circ} 62$ de 26 de agosto de 2003. Diário Oficial da União. 2003 set 18. Portuguese.

13. Vidon DJ, Delmas CL. Incidence of Yersinia enterocolitica in Raw Milk in Eastern France. Applied and Environmental Microbiology, 1981;41(2):355-359.

14. Sambrook J, Russel DW. Molecular cloning: A laboratory manual. $3^{\circ}$ ed. Nova York: Cold Spring Harbor Laboratory Press, 2001. 999 p.

15. Neubauer H, Hensel A, Sojanca A, Herman M. Identification of Yersinia enterocolitica within the Genus Yersinia. Sistematic and applied Microbiology. 2000; 23(1):58-6.

16. CLSI. Clinical and Laboratory Standards Institute. Performance Standards for Antimicrobial Disk Susceptibility Tests. Approved Standard - Twelfth Edition. Pennsylvania, USA, 2015.a 
17. CLSI. Clinical and Laboratory Standards Institute. Performance Standards for Antimicrobial Susceptibility Testing; Twenty-Fifth Informational Supplement. M100-S25. v.35, n.3, 2015.b

18. Simili FF, Lima MLP Como os alimentos podem afetar a composição do leite das vacas. Pesquisa \& Tecnologia, 2007;4(1).

19. Fox PF, Guinee TP, Cogan TM, McSweeney PLH. Fundamental of Cheese Science. Second Edition. 799p. Springer. New York, 2017. English.

20. Forsythe SJ. Microbiologia da Segurança dos Alimentos. 607p. Artmed, Porto Alegre, 2013. Portuguese.

21. Queiroga RCRE, Guerra ICD, Oliveira CEV, Oliveira MEG, Souza EL. Elaboração e caracterização físicoquímica, microbiológica e sensorial de queijo "tipo minas frescal" de leite de cabra condimentado. Revista Ciências Agronômicas, 2009; 40(3):.363-372.

22. Germano P M L, Germano, MIS. Higiene e Vigilância Sanitária de Alimentos. 5a.ed. Manole. Barueri São Paulo, 2013. p.153-169. Portuguese.

23. Zaffari CB, Mello JF, Costa M. Qualidade bacteriológica de queijos artesanais comercializados em estradas do litoral norte do Rio Grande do Sul, Brasil. Ciência Rural, 2007; 37(3):862-867.

24. Brant L M F, Fonseca L M, Silva, M C C. Avaliação da qualidade microbiológica do queijo-de-minas artesanal do Serro-MG. Arquivo Brasileiro de Medicina Veterinária e Zootecnia, 2007;59(6):1570-1574.

25. Franco BDGM., Landgraf M. Microbiologia dos Alimentos. São Paulo: Editora Atheneu, 2008.182p. Portuguese.

26. FDA. Food and Drug Administration. Bad Bug Book, Foodborne Pathogenic Microorganisms and Natural Toxins. Second Edition. [Staphylococcus aureus]. 2012a. Disponível em: https://www.fda.gov/Food/ FoodborneIllnessContaminants/CausesOfIllnessBadBugBook/ Acesso em: 29/05/2017

27. Lima GC, Loiko MR, Casarin LS, Tondo EC. Assessing the epidemiological data of Staphylococcus aureus food poisoning ocurred in the State of Rio Grande do Sul, Southern Brazil. Brazilian Journal of Microbiology, $2013 ; 44(3): 759-763$.

28. Ratti RP, Sousa CP. Staphylococcus aureus meticilina resistente (MRSA) e infecções nosocomiais. Revista de Ciências Farmacêuticas Básica Aplicada. 2009; 30(2):137-143.

29. Costa GM, Barros RA, Custódio DAC, Pereira UP, Figueiredo DJ, Silva N. Resistência a antimicrobianos em Staphylococcus aureus isolados de mastite em bovinos leiteiros de Minas Gerais, Brasil. Arquivos do Instituto Biológico, 2017;80(3): 297-302.

30. Rapini LS, Teixeira JP, Martins NE, Cerqueira MMOP, Sousa MR, Penna CFAM. Perfil de resistência antimicrobiana de cepas de Staphylococcus sp. isoladas de queijo tipo coalho. Arquivo Brasileiro de Medicina Veterinária e Zootecnia, 2004;56(1):130-133.

31. Zafalon LF, Arcaro JRP, Nader Filho A, Ferreira LM, Castelani L, Benvenutto F.Investigação de perfis de resistência aos antimicrobianos em Staphylococcus aureus isolados na ordenha de vacas em lactação. Revista do Instituto Adolfo Lutz, 2008; 67(2):118-125.

32. Hanifian S, Khani S. Prevalence of virulent Yersinia enterocolitica in bulk raw milk and retail cheese in northern-west of Iran. International Journal of Food Microbiology, 2012;155:89-92.

33. FDA. Food and Drug Administration. Bad Bug Book, Foodborne Pathogenic Microorganisms and Natural Toxins. Second Edition. [Yersinia enterocolitica]. 2012b. Disponível em: https://www.fda.gov/Food/ FoodborneIllnessContaminants/CausesOfIllnessBadBugBook/ Acesso em: 29/05/2017. 
34. Brasil. Ministério da Saúde. Surtos de Doenças Transmitidas por Alimentos no Brasil.Informe 2018. Fevereiro de 2019. Disponível em: http://portalarquivos2.saude.gov.br/images/pdf/2019/fevereiro/15/ Apresenta----o-Surtos-DTA---Fevereiro-2019.pdfAcesso em: 11/04/2019.

35. Planzer Jr SB, Cruz AG, Sant'ana AS, Silva R, Moura MRL, Carvalho LMJ. Food Safety Knowledge of Cheese Consumers. Journal of Food Science, 2009; 75(1): 28-30. 